\title{
Islanding of Methyl Radicals: A Key Factor in Hydrocarbon Chain Propagation Reactions
}

\author{
Ping Chuang, ${ }^{\dagger}$ Y. L. Chan, ${ }^{\ddagger}$ Shu-Hua Chien, ${ }^{\dagger}$ K.-J . Song, ${ }^{\S}$ Ruth Klauser," and \\ T. J . Chuang*, $\neq, \S$
}

Center for Condensed Matter Sciences and Department of Physics, National Taiwan University, Taipei 106, Taiwan, Institute of Atomic and Molecular Sciences, Academia Sinica, Taipe, Taiwan, and Synchrotron Radiation Research Center, Hsinchu, Taiwan

Received J anuary 3, 2002. In Final Form: March 25, 2002

\begin{abstract}
A sequence of long-chain alkene products is found to evol ve from chemisor bed methyl groups on $\mathrm{Cu}(111)$ in temperature-programmed reaction. Theresults of low-energy el ectron diffraction measurements suggest the formation of 2D islands for the chemisorbed radicals. The close-packed adsorption geometry and the reaction kinetics to generate high mass species arecl osely correlated. F rom this and other studies, we infer that thetendency of themethyl radical sto aggregate even at submonolayer coverages is crucial in promoting the chain growth, and the observed islanding effect may be significant in other hydrocarbon catalytical systems.
\end{abstract}

\section{Introduction}

Thereexist numerous attempts to mimic heterogeneous catalysis under well-controlled ultrahigh vacuum conditions, in order to understand the basic reaction steps and mechanisms. ${ }^{1-3}$ A number of recent studies ${ }^{3-9}$ haveshown remarkably that Iong-chain hydrocarbons can be produced from single carbon radical species adsorbed on singlecrystal metal surfaces, resembling important aspects of the well-known Fischer-Tropsch reactions. The investigations have yielded certain insight into the general reaction schemes, but a full account of the crucial factors controlling thereaction ratesand product branching ratios is still lacking. In particular, the adsorbate structures and lateral effects have rarely been considered in prior works. Recently, there has been growing interest in understanding the influence of adsorbate-adsorbate interaction and island formation on surface reaction kinetics. A well-known system exhibiting the islanding behavior is the $\mathrm{CO}$ oxidation reaction which has been studied both theoretically and experimentally. ${ }^{10-12}$ Like wise, the oxidation of methyl formate was demonstrated to occur quite localized at the end of $(2 \times 1) \mathrm{O}$ rows on $\mathrm{Cu}(110) .{ }^{13}$ The effects of adsorbateaggregation on thermal desorption spectra of nitrogen were also examined. ${ }^{14}$ It

\footnotetext{
* Corresponding author. Fax: +886-2-2365-5404. E-mail: chuangtj @ccms.ntu.edu.tw.

${ }^{\dagger}$ Department of Chemistry.

₹ Center for Condensed Matter Sciences.

$\S$ Institute of Atomic and Molecular Sciences.

" Synchrotron Radiation Research Center.

(1) Zaera, F. Chem. Rev. 1995, 95, 2651.

(2) Somorjai, G. A. Chem. Rev. 1996, 96, 1223

(3) Bent, B. E. Chem. Rev. 1996, 96, 1361.

(4) Chiang, C. M.; Bent, B. E. Surf. Sci. 1992, 279, 79.

(5) Lin, J. L.; Bent, B. E. J . Vac. Sci. Technol., A 1992, 10, 2202.

(6) Chiang, C. M.; Wentzlaff, T. H.; Bent, B. E.J . Phys. Chem. 1992 96, 1836.

(7) Lin, J . L.; Chiang, C. M.; J enks, C.J .; Yang, M. X.; Wentzlaff, T. H.; Bent, B. E. J . Catal. 1994, 147, 250.

(8) Kim, S. H.: Stair, P. C. J Am. Chem. Soc. 1998, 120, 8535.

(9) Kim, S. H.; Stair, P. C. J. Phys. Chem. B 2000, 104, 3035.

(10) Hellsing, B.; Zhdanov, V. P. Chem. Phys. Lett. 1988, 147, 613

(11) Silverberg, M.; Ben-Shaul, A. Chem. Phys. Lett. 1987, 134, 491.

(12) Wintterlin, J.; Volkening, S.; J anssens, T. V. W.; Zambelli, T. Ertl, G. Science 1997, 278, 1931.

(13) Silva, S. L.; Patel, A. A.; Pham, T. M.; Leibsle, F. M. Surf. Sci.
} $1999,441,351$ appears, however, that in the hydrocarbon surface chemistry, the islanding phenomenon of $\mathrm{CH}_{\mathrm{x}}$ radicals and its effect on thechain propagation reactions have never been reported. We present here some striking observations on $\mathrm{Cu}(111)$ surface exposed to methyl $\left(\mathrm{CH}_{3}\right)$ radicals to shed some light into the problem. It was found not only that a series of high mass alkyl products can be generated in a relatively mild thermal process but also that they can evolvefrom themetal surfaceall at thesametemperature. Furthermore, such reactions can take placeeven at a very small surface coverage. By examining the adsorbatesurface topographic structure as a function of surface coverage and temperature, and correlating the structure with the thermal chemistry, we conclude that islanding of the chemi sorbed methyl radicals must play a key role in facilitating the chain propagation process. To our knowledge, it is the first observation of two-dimensional island formation on a metal surface exposed to such radicals.

\section{Experimental Section}

The experiments were carried out in a ultrahigh vacuum system equipped with a high-resolution electron energy loss spectrometer (HREELS), X-ray photoemission (XPS), temperature-programmed desorption (TPD) with a quadrupole mass spectrometer (QMS), and low-energy el ectron diffraction (LEED) as described previously. ${ }^{15,16} \mathrm{M}$ ethyl radicals weregenerated from azomethane gas passed through a hot quartz nozzle source ${ }^{8,9,15-18}$ and dosed directly onto the $\mathrm{Cu}(111)$ surface. The adsorbed hydrocarbons were analyzed by XPS and HREELS, the surface structure by LEED, and the gaseous products by TPD. Thetotal adsorbate coverage $(\theta)$ averaged over the sample surface was determined quantitatively by the attenuation of $\mathrm{Cu} 2 \mathrm{p}$ XPS signal $^{16}$ and from TPD spectra. F or LEED measurements, the charge deposition on the sample was carefully controlled to minimize the electron irradiation effect, and the patterns were recorded by a CCD camera.

(14) Hood, E. S.; Toby, B. H.; Weinberg, W. H. Phys. Rev. Lett. 1985, 55,2437

(15) Chan, Y. L.; Chuang, P.; Chuang, T. J . J . Vac. Sci. Technol., A 1998, 16, 1023

(16) Chuang, T.J .; Chan, Y. L.; Chuang, P.; Klauser, R. J . Electron Spectrosc. Relat. Phenom. 1999, 98/ 99, 149.

(17) Peng, X. D.; Viswanathan, R.; Smudde, G. H.J .; Stair, P. C. Rev. Sci. Instrum. 1992, 63, 3930.

(18) Dickens, K. A.; Stair, P. C. Langmuir 1998, 14, 1444. 


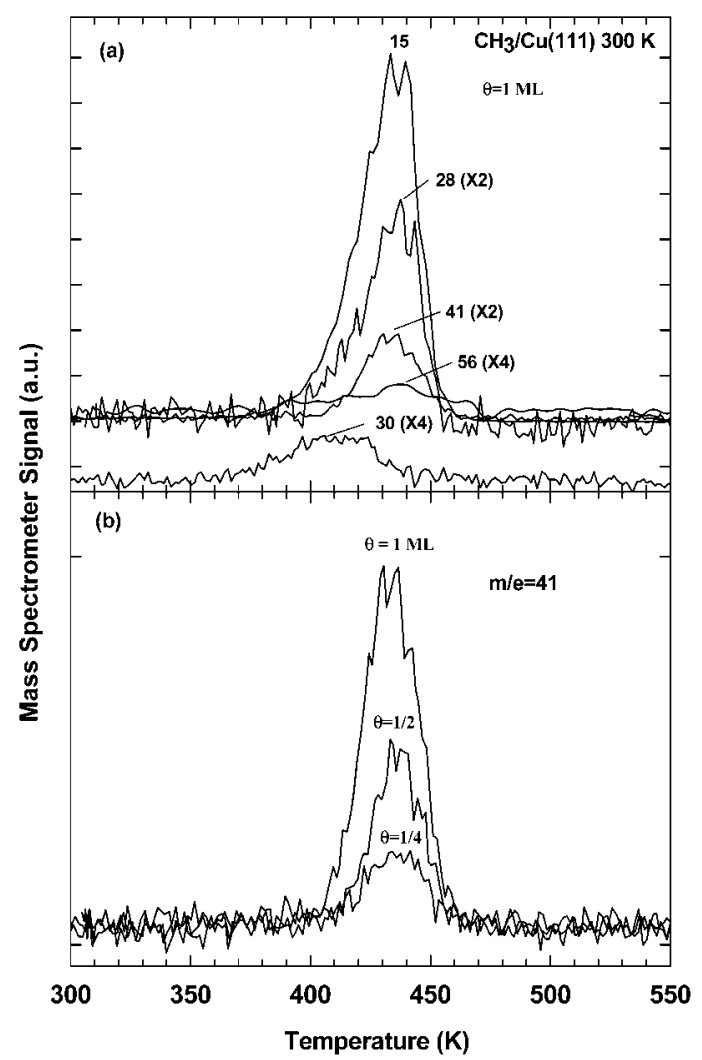

Figure 1. TPD spectra: (a) monitoring $\mathrm{m} / \mathrm{e}=15\left(\mathrm{CH}_{4}\right), 28$ $\left(\mathrm{C}_{2} \mathrm{H}_{4}\right), 30\left(\mathrm{C}_{2} \mathrm{H}_{6}\right), 41\left(\mathrm{C}_{3} \mathrm{H}_{6}\right)$, and $56\left(\mathrm{C}_{4} \mathrm{H}_{8}\right)$ signals for adsorbed $\mathrm{CH}_{3}$ with 1 monolayer coverage on $\mathrm{Cu}(111)$ at $300 \mathrm{~K}$; (b) monitoring $\mathrm{m} / \mathrm{e}=41\left(\mathrm{C}_{3} \mathrm{H}_{6}\right)$ signals at $0.25,0.5$, and 1.0 monolayer $\mathrm{CH}_{3}$ surface coverages.

\section{Results and Discussion}

As shown in our prior work, ${ }^{15,16} \mathrm{CH}_{3}$ (ads) chemisorption is readily detected by XPS and HREELS when the clean $\mathrm{Cu}(111)$ surface at $300 \mathrm{~K}$ is exposed to the radical source. Thereis no $\mathrm{N}$-containing species or any other contaminant. The chemisorption of the radicals, however, is accompanied by some dissociation into $\mathrm{CH}_{2}$ (ads) and $\mathrm{H}$ (ads), possi bly around the surface defect sites. Figurela depicts the TPD spectra for various masses when a monolayer $(\theta$ $=1$ monolayer, saturation coverage at $300 \mathrm{~K}$, invariable with theamount of $\mathrm{CH}_{3}$ exposure) of adsorbates is heated at $3 \mathrm{~K} / \mathrm{s}$ from 300 to $600 \mathrm{~K}$. The primary gaseous products are $\mathrm{CH}_{4}, \mathrm{C}_{2} \mathrm{H}_{4}, \mathrm{C}_{2} \mathrm{H}_{6}, \mathrm{C}_{3} \mathrm{H}_{6}$, and $\mathrm{C}_{4} \mathrm{H}_{8}$ molecules. The molecular entities of these species are determined by measuring therelativesignal intensities at various masses and comparing those with thecracking patterns of known molecules by our quadrupole mass spectrometer. For instance, mass signals at 26, 27, and 28 amu are used to identify $\mathrm{C}_{2} \mathrm{H}_{4}, 39,41$, and 42 amu for $\mathrm{C}_{3} \mathrm{H}_{6}$ (propylene), and 41 and 56 amu for $\mathrm{C}_{4} \mathrm{H}_{8}$ (1-butene). At a submonolayer coverage, the high mass species $\left(\mathrm{C}_{3} \mathrm{H}_{6}\right.$ and $\left.\mathrm{C}_{4} \mathrm{H}_{8}\right)$ are still detectable, al though thesignal strengths aresubstantially weaker. Figure $1 \mathrm{~b}$ exhibits the TPD signals for $\mathrm{C}_{3} \mathrm{H}_{6}$ as a function of surface coverage ( $\theta$ in monolayers). Clearly $\mathrm{C}_{3} \mathrm{H}_{6}$ can be produced even at $\theta \leq 0.2$ monolayers. It is worth noting that butene or a higher mass product has never been observed in prior works for $\mathrm{CH}_{3} / \mathrm{Cu}$ systems with $\mathrm{CH}_{3} \mathrm{l}$ as thereagent. ${ }^{3-7} \mathrm{~F}$ urthermore, our TPD spectra always exhibit a single desorption peak for all hydrocarbon species at all gaseous exposures. This fact shows that at saturation coverage, $\theta$ is indeed 1 monol ayer and there is no multilayer adsorption.
The results show remarkably that long-chain alkenes can be readily produced from chemisorbed $\mathrm{CH}_{3}$ radicals all at the sametime in a temperature ramp. In the present system, we find that $\mathrm{CH}_{4}, \mathrm{C}_{2} \mathrm{H}_{4}, \mathrm{C}_{3} \mathrm{H}_{6}$, and $\mathrm{C}_{4} \mathrm{H}_{8}$ products are generated at the same temperature of $437 \mathrm{~K}( \pm 3 \mathrm{~K})$ under the given condition. Mor eover, the peak desorption temperature is independent of initial $\mathrm{CH}_{3}$ surface coverage. This implies thefirst-order reaction kinetics for those products. In contrast, the TPD peak for $\mathrm{C}_{2} \mathrm{H}_{6}$ is around $410 \mathrm{~K}$ (also displayed in Figure 1a), and this value shifts from $420 \mathrm{~K}$ at $\theta=0.3$ monolayer to $408 \mathrm{~K}$ at $\theta=1$ monolayer. The reaction and desorption exhibit the characteristics of second-order kinetics, and the product is apparently due to the direct coupling of two $\mathrm{CH}_{3}$ (ads) radicals. In prior studies on Cu surfaces by Bent et al. ${ }^{3-7}$ with $\mathrm{CH}_{3} \mathrm{l}$ as the source for $\mathrm{CH}_{3}$ radicals, $\mathrm{CH}_{4}, \mathrm{C}_{2} \mathrm{H}_{4}$, and $\mathrm{C}_{3} \mathrm{H}_{6}$ production and desorption were detected at $450 \mathrm{~K}$ on $\mathrm{Cu}(111)^{5}$ and at $470 \mathrm{~K}$ on $\mathrm{Cu}(100)^{7}$ independent of surface coverage. $\mathrm{F}$ or $\mathrm{CH}_{3}$ generated the same way as the present study but adsorbed on oxygen-modified $\mathrm{Mo}(100)$, $\mathrm{Kim}$ and Stair ${ }^{8,9}$ reported the formation of $\mathrm{CH}_{4}, \mathrm{C}_{2} \mathrm{H}_{4}$, $\mathrm{C}_{3} \mathrm{H}_{6}, \mathrm{C}_{4} \mathrm{H}_{8}$, and $\mathrm{C}_{5} \mathrm{H}_{10}$ at nearly the same temperature of $440 \mathrm{~K}$. Apparently, in all these $\mathrm{CH}_{3} /$ surfacesystems, there are common molecular production, desorption characteristics, and reaction kinetics. I n theprevious investigations, it was proposed that some $\mathrm{CH}_{3}$ (ads) radicals were decomposed to form $\mathrm{CH}_{2}$ (ads) groups which subsequently reacted with intact $\mathrm{CH}_{3}$ to generate $\mathrm{C}_{2+}$ alkyl products. Specifically, Bent's research group has suggested $\mathrm{CH}_{3}$ dissociation by $\alpha$-eli mination of a hydrogen atom to bethe rate-limiting step for the chain reactions. Namely, the reaction scheme can be represented by $\mathrm{CH}_{3}$ (ads) $\rightarrow \mathrm{CH}_{2-}$ (ads) $+\mathrm{H}$ (ads), followed by $\mathrm{CH}_{3}$ (ads) $+\mathrm{H}$ (ads) $\rightarrow \mathrm{CH}_{4}(\mathrm{~g}) \uparrow$ and $\mathrm{CH}_{3}$ (ads) $+\mathrm{CH}_{2}$ (ads) $\rightarrow \mathrm{C}_{2} \mathrm{H}_{5}$ (ads) $\rightarrow \mathrm{C}_{2} \mathrm{H}_{4}(\mathrm{~g}) \uparrow+$ $\mathrm{H}$ (ads). Subsequently, the $\mathrm{C}_{3}$ product can be generated by $\mathrm{C}_{2} \mathrm{H}_{5}+\mathrm{CH}_{2} \rightarrow \mathrm{C}_{3} \mathrm{H}_{7} \rightarrow \mathrm{C}_{3} \mathrm{H}_{6}(\mathrm{~g}) \uparrow+\mathrm{H}$, and by extension higher mass species can beformed by $\mathrm{C}_{3} \mathrm{H}_{7}+\mathrm{CH}_{2} \rightarrow \mathrm{C}_{4} \mathrm{H}_{9}$ $\rightarrow \mathrm{C}_{4} \mathrm{H}_{8}(\mathrm{~g}) \uparrow+\mathrm{H}, \ldots$, etc. I $n$ other words, thereis a sequential methylene insertion at the $\alpha$-carbon position into the transient alkyl species to produce longer carbon chains. There is experimental evidenceto support such a reaction scheme. ${ }^{3-9}$ It should benoted that according to the scheme, the fate of the transient species such as $\mathrm{C}_{2} \mathrm{H}_{5}$ and $\mathrm{C}_{3} \mathrm{H}_{7}$ is either desorption by dehydrogenation or reaction with another $\mathrm{CH}_{2}$ for the chain growth. The critical question to ask in the present as well as previous systems is why the reactions leading to the $\mathrm{C}_{3+}$ alkyl products can occur all at nearly the same temperature and independent of surface coverage. We have detected $\mathrm{C}_{3} \mathrm{H}_{6}$ formation even at $\theta$ less than 0.2 monol ayer. How can this take place via the sequential reaction process when the surface is, on the average, so sparsely occupied by the radicals?

To resolve this puzzle, we decided to look further into the adsorption geometry and dynamic behavior of $\mathrm{CH}_{3}$ radicals on $\mathrm{Cu}(111)$ by use of the LEED technique. Panels $a$ and $b$ of Figure2 depict the LEED patterns at $\theta=0.25$ and 1.0 monolayers with $\mathrm{Cu}(111)$ at $300 \mathrm{~K}$. At saturation coverage, the LEED pattern exhibits six bright spots indicative of $(\sqrt{ } 3 \times \sqrt{ } 3) R 30^{\circ}$ superstructure. In addition, there is a dim hexagon-like structure connecting the $(\sqrt{ } 3 \times \sqrt{ } 3)$ R30 $0^{\circ}$ spots. This pattern of discrete spots with the diffuse hexagon structure is still clearly visible at 380 $\mathrm{K}$ (Figure 2c) and even momentarily at $420 \mathrm{~K}$ (Figure 2d). At $450 \mathrm{~K}$ or higher, the LEED intensity due to the adsorbate disappears when the reaction is completed. As the initial $\theta$ decreases, the spots due to $(\sqrt{ } 3 \times \sqrt{ } 3) \mathrm{R} 30^{\circ}$ superstructure fade away while the diffuse hexagon pattern gains intensity. F or low coverage samples with only a diffuse hexagon pattern at $300 \mathrm{~K}$, cooling to $120 \mathrm{~K}$ 

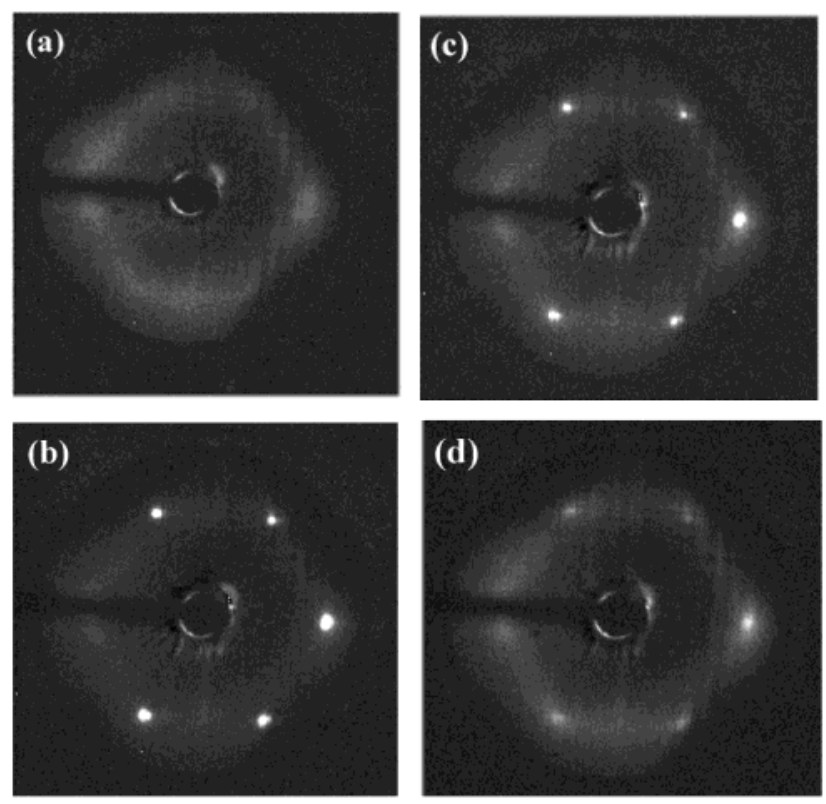

Figure 2. LEED (e-beam energy $\mathrm{E}=30 \mathrm{eV}$ ) patterns of $\mathrm{CH}_{3}$ on $\mathrm{Cu}(111)$ at $300 \mathrm{~K}$ with $\mathrm{CH}_{3}$ coverages of (a) $\theta=0.25$ monolayer and (b) $\theta=1.0$ monolayer. The temperature of sample (b) is then raised to $380 \mathrm{~K}$ (c) and $420 \mathrm{~K}$ (d)
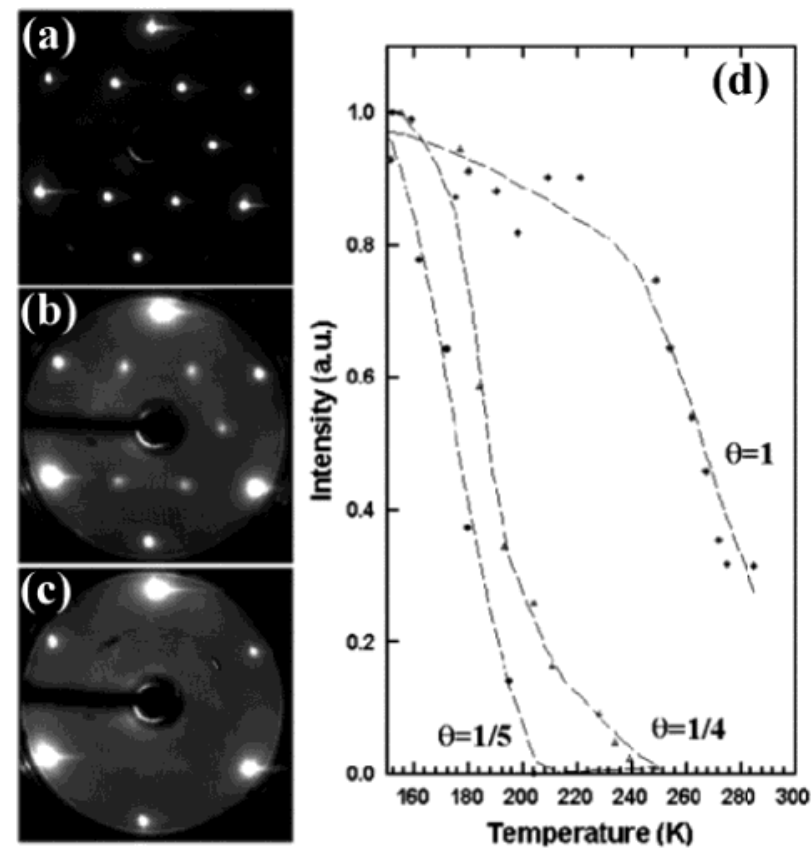

Figure 3. LEED $(E=67 \mathrm{eV})$ patterns of $\theta=0.3$ monolayer of $\mathrm{CH}_{3}$ on $\mathrm{Cu}(111)$ at $120 \mathrm{~K}(\mathrm{a})$ and raised to $210 \mathrm{~K}(\mathrm{~b})$ and 300 $K$ (c). The intensities of (a) and (c) are amplified by a factor of 2 to show the details. The bright spots at outermost positions (six spots) are from $\mathrm{Cu}(111)$ substrate. These substrate diffraction spots are visible on a LE ED screen with $\mathrm{E}=67 \mathrm{eV}$ (but invisible with $E=30 \mathrm{eV}$ as in Figure 2). (d) Sum of the spots intensities of $(\sqrt{ } 3 \times \sqrt{ } 3) R 30^{\circ}$ structure as a function of temperature at various $\mathrm{CH}_{3}$ coverages as indicated.

causes the $(\sqrt{ } 3 \times \sqrt{ } 3) R 30^{\circ}$ spots to show up. The LEED patterns with $\theta=0.3$ monolayer at various temperatures are displayed in panels a-c of Figure 3. Such a transition is reversible. If the sample temperature is raised again, the discrete spots fade away while the hexagon pattern becomes more pronounced. As shown in Figure 3d, the temperature range where the discrete spots disappear depends strongly on coverage. The higher the coverage, thehigher thetemperaturethediscretespots can survive. The transition temperature (i.e., at the point that the intensity of a discrete spot decreases to one-half of its low $\mathrm{T}$ value) also depends on the annealing history of the sample, being higher if the sample has been annealed at a higher temperature. It should bementioned clearly that $\theta$ remains constant when thesubstrate $T$ is varied between 120 and $350 \mathrm{~K}$.

To interpret the LEED data, we have to consider the sizeof a methyl group and its possi bleadsorption geometry. Notethat the van der Waals diameter of $4 \AA$ for a methyl group is much larger than the nearest neighbor $\mathrm{Cu}-\mathrm{Cu}$ distance of $2.55 \AA$. It is thus inevitable to cause space hindrance if onetries to put morethan one methyl radical into one $(\sqrt{ } 3 \times \sqrt{ } 3)$ R $30^{\circ}$ unit cell. Our ab initiocal culations indicate that adsorption of two methyl radicals per $(\sqrt{3} \times \sqrt{ } 3) \mathrm{R} 30^{\circ}$ unit cell is possible, but the adsorption energy per methyl is reduced by a large amount of $0.6 \mathrm{eV}$ (compared with one methyl per unit cell case). In such "doubly packed" geometry, the $\mathrm{CH}_{3}$ groups cannot freely rotate. Thus, a less densely packed structure is clearly favored. Since cooling a low-coverage sample can cause spontaneous conversion to the $(\sqrt{3} \times \sqrt{ } 3) \mathrm{R} 30^{\circ}$ structure, this strongly suggests that the $(\sqrt{ } 3 \times \sqrt{ } 3) \mathrm{R} 30^{\circ}$ structure formed by cooling has only one methyl per unit cell.

At $\theta$ below 0.5 monolayer, we always obtain LEED patterns with a diffusehexagon at $300 \mathrm{~K}$. Closeinspection of the hexagons reveals that they only have 3-fold rotational symmetry. The diffuse nature of the pattern suggests the real space structure to be highly di sordered. At this stage, few specifics of this structure are known. We postulate that the structure consists of two-dimensional (2D) islands of "liquidlike" (i.e., highly disordered but condensed) methyl radicals. It is well-known that the melting temperature of 3D clusters reduces significantly as their sizes become smaller. ${ }^{19}$ It is thus plausible to postulate the transition temperature between the 2D liquidlike phase, and the ordered $(\sqrt{ } 3 \times \sqrt{ } 3) \mathrm{R} 30^{\circ}$ phase also reduces significantly as the size of the $2 \mathrm{D}$ islands shrinks. It is well established that the growth of an epitaxial film proceeds first through a nucleation stage and then through a growth stage. ${ }^{20}$ In the growth stage, the number of islands quite often stays fixed while each island grows in size as deposition proceeds. The average size of the 2D islands is determined by the average coverage divided by the fixed number density of islands, and thereforeit is proportional to the coverage. From this consideration, theobserved higher transition temperature for higher coverage can be easily understood as due to the larger island size.

Even after deposition, if surface diffusion is effective at the given temperature, the islands can undergo coarsening $^{21}$ in which theaveragesize of the 2D islands gradually increases. Such increase is especially prominent when the sampletemperature is raised toa high level bel ow the onset of thermal desorption. Thus one would predict that theorder-disorder transiti on temperature of themethylcovered surface to be an increasing function of the maximum temperaturethesamplehas ever been annealed at. This prediction turns out to be true. For instance, we have prepared a sample by dosing at $265 \mathrm{~K}$ until $\theta=0.3$ monolayer and then cooled to $120 \mathrm{~K}$. With the sample heated slowly, the transition temperature is found to be $207 \mathrm{~K}$. The same sample is then annealed at $320 \mathrm{~K}$ and

(19) Lai, S. L.; Guo, J . Y.; Petrova, V.; Ramanath, G.; Allen, L. H. Phys. Rev. Lett. 1996, 77, 99.

(20) Thiel, P. A.; Evans, J. W. J . Phys. Chem. 2000, 104, 1663

(21) Pai, W. W.; Swan, A. K.; Zhang, Z.; Wendelken, J . F. Phys. Rev. Lett. 1997, 79, 3210. 
cool ed to $120 \mathrm{~K}$. By heating at the same rate again, the transition temperature is now found to be $217 \mathrm{~K}$. This increase supports the idea that the methyl radicals have a natural tendency toaggregateintoever larger $2 \mathrm{D}$ islands at higher temperatures. Furthermore, we have investigated the tendency of islanding even when the methyl radicals have enough energy to react. For a sample with near saturation coverage, wefind theintegrated intensity of the hexagon increases with $\mathrm{T}$, reaches the maximum around $400-440 \mathrm{~K}$, and then finally disappears completely when all the hydrocarbon radicals are depleted by the thermal reactions and desorption. Thistemperaturerange of $400-440 \mathrm{~K}$ is exactly the same as that of long-chain alkyl production detected by TPD (Figure 1). Thus, the disordered phase indeed can survive at the reaction temperature.

Theability toform 2D islands for theradical adsorbates regardless of thetotal surface coverageseems to becrucial for thealkyl chain propagation reactions. I $\mathrm{n}$ the proposed scheme for $\mathrm{C}_{3} \mathrm{H}_{6}$ and $\mathrm{C}_{4} \mathrm{H}_{8}$ production via $\mathrm{CH}_{2}$ insertion mechanism, thetransient $\mathrm{C}_{2} \mathrm{H}_{5}$ (ads) and $\mathrm{C}_{3} \mathrm{H}_{7}$ (ads) species have to react effectively with $\mathrm{CH}_{2}$ (ads) within their relatively short lifetimes, in competition with the desorption channel. If the chemisorbed $\mathrm{CH}_{3}$ (ads) and $\mathrm{CH}_{2}$ (ads) radicals were to reside sparsely and far away from the transient species, there would be little chance for the formation of $\mathrm{C}_{3+}$ species. Surface diffusion could be too slow for the reaction process. In the 2D island structure, the radicals are close neighbors even at a very small (average) surface coverage. Such adsorption geometry can greatly enhance the chemical reactivity.

\section{Conclusion}

In the temperature-programmed reaction and desorption measurements, a series of high mass hydrocarbon products, up to $\mathrm{C}_{4} \mathrm{H}_{8}$, are observed from the chemisorbed $\mathrm{CH}_{3}$ (ads) groups on $\mathrm{Cu}(111)$. Thelong-chain alkyl species evolve from the surface all at the same temperature and independent of theinitial surfacecoverage $(\ll 1$ monolayer). Such reaction behavior and kinetics can be understood based on a close-packed adsorption geometry which is verified by LEED measurements. The study shows that $\mathrm{CH}_{3}$ (ads) groups tend to aggregate in forming 2D islands with $(\sqrt{ } 3 \times \sqrt{ } 3) \mathrm{R} 30^{\circ}$ structure even at submonolayer coverages. The close proximity of the reactants is apparently essential in facilitating the chain propagation reactions initiated by $\mathrm{CH}_{2}$ (ads) formation followed by the methylene insertion process. We therefore conclude that the islanding behavior is a key factor in promoting chain reactions to generate high mass alkyl products. The observed effect may have a wide implication in heterogeneous catalysis.

Acknowledgment. The authors wish to thank the National Science Council and the Ministry of Education of R.O.C. for support of this work.

\section{LA020016Y}

